\title{
Effect of high and low glycaemic index recovery diets on intramuscular lipid oxidation during aerobic exercise
}

\author{
Michael I. Trenell ${ }^{1 *}$, Emma Stevenson ${ }^{2}$, Karola Stockmann ${ }^{3}$ and Jennie Brand-Miller ${ }^{3}$ \\ ${ }^{1}$ Diabetes Research Group \& Newcastle Magnetic Resonance Centre, School of Clinical Medical Sciences, Newcastle University, \\ Newcastle upon Tyne, UK \\ ${ }^{2}$ School of Psychology and Sports Science, Northumbria University, Newcastle upon Tyne, UK \\ ${ }^{3}$ Human Nutrition Unit, School of Molecular and Microbial Biosciences, University of Sydney, Sydney, Australia
}

(Received 28 February 2007 - Revised 22 May 2007 - Accepted 22 June 2007)

Intramyocellular lipid (IMCL) and plasma NEFA are important skeletal muscle fuel sources. By raising blood insulin concentrations, carbohydrate ingestion inhibits lypolysis and reduces circulating NEFA. We hypothesised that differences in the postprandial glycaemic and insulin response to carbohydrates (i.e. glycaemic index; GI) could alter NEFA availability and IMCL use during subsequent exercise. Endurance-trained individuals ( $n$ 7) cycled for $90 \mathrm{~min}$ at $70 \% \mathrm{~V}_{2 \text { peak }}$ and then consumed either high GI (HGI) or low GI (LGI) meals over the following $12 \mathrm{~h}$. The following day after an overnight fast, the 90 min cycle was repeated. IMCL content of the vastus lateralis was quantified using magnetic resonance spectroscopy before and after exercise. Blood samples were collected at $15 \mathrm{~min}$ intervals throughout exercise and analysed for NEFA, glycerol, glucose, insulin, and lactate. Substrate oxidation was calculated from expired air samples. The $90 \mathrm{~min}$ cycle resulted in $>2$-fold greater reduction in IMCL in the HGI trial (3.5 (SEM 1.0) mM/kg wet weight) than the LGI trial (1.6 (SEM 0.3) mM/kg wet weight, $P<0.05$ ). During exercise, NEFA availability was reduced in the HGI trial compared to the LGI trial (area under curve 2.36 (SEM 0.14) mEq/l per h $v .3 .14$ (SEM 0.28) $\mathrm{mEq} / 1 \mathrm{per} \mathrm{h,} P<0 \cdot 05 \mathrm{respect}$ ively). No other differences were significant. The findings suggest that HGI carbohydrates reduce NEFA availability during exercise and increase reliance on IMCL as a substrate source during moderate intensity exercise.

Glycaemic index: Intramyocellular lipid: Magnetic resonance spectroscopy: Exercise: Skeletal muscle

During moderate intensity exercise, the energy for ATP homeostasis in skeletal muscle is primarily obtained from the oxidation of glycogen and lipid. Glycogen plays a pivotal role in producing energy and preventing the development of muscle fatigue in submaximal exercise ${ }^{1-4}$. Intramuscular lipid levels are also readily oxidised during prolonged exercise $^{5-7}$ and are elevated in endurance-trained individuals ${ }^{8}$. The rate of substrate oxidation, whether glycogen or lipid, is influenced by both existing pre-exercise substrate within the muscle $^{9}$, and circulating substrate availability during exercise $\mathrm{e}^{10-13}$. Although considerable work has been undertaken on optimising glycogen storage with diet, less is known about the relative influence of diet upon both glycogen and lipid oxidation.

High levels of carbohydrate intake have been shown to improve glycogen repletion after exercise ${ }^{14,15}$. An early study also reported that consuming carbohydrates which are rapidly absorbed into the circulatory system, termed high glycaemic index (HGI) carbohydrates, optimised the storage of plasma glucose as skeletal muscle glycogen following glycogen-depleting exercise ${ }^{16}$. It has also been reported that the postprandial hyperinsulinaemia accompanying high carbohydrate intake reduces the rate of fat oxidation ${ }^{17-19}$, increasing reliance upon glycogen oxidation during exercise. Although high postprandial levels of insulin may increase glycogen storage, the suppression of peripheral lypolysis may increase dependency upon intramuscular stores of glycogen and lipid during exercise $\mathrm{e}^{20}$.

Plasma NEFA are esterified to form intramyocellular lipid (IMCL) in non-contracting muscle and are oxidised during exercise ${ }^{21,22}$. During moderate intensity exercise $\left(40-65 \% \dot{\mathrm{V}}_{2 \max }\right)$ fat oxidation contributes $40-60 \%$ of the total energy expenditure $5,6,17,23$. Of the total fat oxidised, $50-70 \%$ is derived from plasma NEFA with the remaining proportion obtained from intramuscular and lipoproteinderived $\mathrm{TAG}^{24}$. The postprandial rise in insulin suppresses lypolysis, thereby decreasing circulating NEFA available for storage as IMCL and oxidation in skeletal muscle ${ }^{17,25}$. Artificially elevating circulating NEFA levels increases lipid oxidation and reduces glycogen use in exercise $\mathrm{e}^{10-13}$, reinforcing the relationship between lipid and glycogen oxidation.

It is possible that optimising glycogen resynthesis with a HGI recovery diet occurs at the cost of compromised NEFA availability ${ }^{17-19}$. Maintaining lipid availability with a low

Abbreviations: FFA, free fatty acids; GI, glycaemic index; HGI, high GI; LGI, low GI; IMCL, intramyocellular lipid; MRS, magnetic resonance spectroscopy; $\dot{\mathrm{V}} \mathrm{O}_{2 \text { peak }}$, peak $\dot{\mathrm{V}} \mathrm{O}_{2}$.

* Corresponding author: Dr Mike Trenell, fax +44 191256 3692, email m.i.trenell@ncl.ac.uk 
glycaemic index (LGI) diet may therefore assist endurance exercise performance. We hypothesised that LGI meals consumed after prolonged endurance exercise improve fatty acid availability and reduce reliance on IMCL in subsequent bouts of exercise. To test this hypothesis, LGI or HGI meals were consumed during a $24 \mathrm{~h}$ recovery period following $90 \mathrm{~min}$ of moderate intensity cycling. After an overnight fast, IMCL was examined using ${ }^{1} \mathrm{H}$-magnetic resonance spectroscopy (MRS) before and after a second $90 \mathrm{~min}$ cycle. Venous blood samples were collected to observe changes in circulating lipids, glucose, insulin and lactate. Expired air samples were collected to evaluate changes in substrate use during exercise.

\section{Subjects and methods}

\section{Subject information and initial testing}

Seven endurance-trained male cyclists (30 (SEM 6) years of age, 80 (SEM 8) kg body weight) gave written informed consent. The study was approved by the Central Sydney Area Health, Human Ethics Research Committee, Sydney, Australia. Peak $\dot{\mathrm{VO}}_{2}\left(\dot{\mathrm{V}}_{2 \text { peak }}\right)$ was determined whilst cycling on a stationary cycle ergometer using four 5 min steady state stages $(100,150,200$ and $250 \mathrm{~W})$ followed by a progressive increase in work of $10 \mathrm{~W} / \mathrm{min}$ until voluntary exhaustion and averaged 4.6 (SEM $0 \cdot 2$ ) $1 / \mathrm{min}$. All exercise tests were conducted on the same electronically braked cycle ergometer (Tunturi E85, Tunturi, Turku, Finland).

\section{Pre-trial exercise}

After a $12 \mathrm{~h}$ fast, participants undertook a 90 min cycle at $70 \%$ $\dot{\mathrm{VO}}_{2 \text { peak }}$ in the laboratory starting at 08.00 hours. Work rate (W) at $70 \% \dot{\mathrm{V}}_{2 \text { peak }}$ was calculated for each individual from the linear function of $\mathrm{O}_{2}$ uptake at the four steadystate work rates and maximal $\mathrm{O}_{2}$ uptake against the work rate $(\mathrm{W})$ of the four steady-state work rates and maximal power output. Mean work rate at $70 \% \dot{\mathrm{V}}_{2 \text { peak }}$ was 216 (SEM 8) W. During the cycle, water was provided ad libitum. During subsequent cycle trials, the same amount of water was consumed.

\section{Dietary manipulation}

At the end of the first 90 min cycle, participants were provided with food for the following $24 \mathrm{~h}$ containing either a HGI or LGI carbohydrate component. The treatment order of the interventions was randomised. Carbohydrate was provided at $8 \mathrm{~g} / \mathrm{kg}$ body mass with protein and fat content constituting 11 and $17 \%$ of energy respectively (see Table 1 for details). The glycaemic index (GI) values were calculated from international tables ${ }^{26}$. Breakfast was provided at the research facility. Packaged lunch, dinner and snacks were provided for the subject to consume at home. Water could be consumed ad libitum with no other drinks allowed. Participants were asked to only eat the food provided and to finish eating the food before 21.00 hours that night.

\section{Experimental trial protocol}

Participants arrived in the laboratory $24 \mathrm{~h}$ after the first $90 \mathrm{~min}$ cycle participants arrived in the laboratory and were weighed in minimal clothing. An indwelling cannula was then inserted into the cephalic vein for blood sampling. Magnetic resonance examinations were completed $0.5 \mathrm{~h}$ before and $1 \mathrm{~h}$ after the end of the experimental trial cycle (see later). Following a 10 min warm- up at a self-selected pace, participants cycled for $90 \mathrm{~min}$ at $70 \%$ of their $\dot{\mathrm{VO}}_{2 \text { peak }}$ Expired air samples were collected for $2 \mathrm{~min}$ at $15,30,45,60,75$ and $90 \mathrm{~min}$ time points and analysed online for expired fractions of $\mathrm{O}_{2}$, $\mathrm{CO}_{2}$ and ventilation (Cortex Biophysik, Leipzig, Germany). Substrate oxidation rates were calculated using non-protein

Table 1. Nutrient content of the high $(\mathrm{H})$ and low $(\mathrm{L})$ glycaemic index (GI) diets (for a $70 \mathrm{~kg}$ person)

\begin{tabular}{|c|c|c|}
\hline \multirow[b]{2}{*}{ Meal component* } & \multicolumn{2}{|c|}{ Diet } \\
\hline & $\mathrm{HGI}$ & LGI \\
\hline \multicolumn{3}{|l|}{ Breakfast } \\
\hline Corn flakes (g) & 60 & - \\
\hline White bread (g) & 70 & - \\
\hline Jam (g) & 30 & - \\
\hline Margarine (g) & 5 & - \\
\hline Carbonated glucose drink (ml) & 140 & - \\
\hline Skimmed milk (ml) & 250 & 250 \\
\hline Guardian Cereal (g) & - & 85 \\
\hline Apple (g) & - & 70 \\
\hline Canned peaches $(\mathrm{g})$ & - & 130 \\
\hline Yoghurt (g) & - & 100 \\
\hline Apple juice (ml) & - & 400 \\
\hline \multicolumn{3}{|l|}{ Lunch / Dinner } \\
\hline Turkey (g) & 100 & 100 \\
\hline Lettuce (g) & 50 & 50 \\
\hline Cheese (g) & 50 & 50 \\
\hline White bread (g) & 154 & - \\
\hline Banana (g) & 175 & - \\
\hline Carbonated glucose drink $(\mathrm{mL})$ & 200 & - \\
\hline Wholemeal pasta $(\mathrm{g})$ & - & 150 \\
\hline Pasta sauce $(\mathrm{g})$ & - & 170 \\
\hline Pear $(\mathrm{g})$ & - & 100 \\
\hline Apple juice (g) & - & 145 \\
\hline \multicolumn{3}{|l|}{ Snacks } \\
\hline Carbonated glucose drink (ml) & 95 & - \\
\hline Grain snack bar (g) & 77 & - \\
\hline Apple juice (ml) & - & 550 \\
\hline Fruit snack (g) & - & 80 \\
\hline \multicolumn{3}{|l|}{ Macronutrient content } \\
\hline Energy (KJ) & 3244 & 3263 \\
\hline Carbohydrate (g) & 561 & 555 \\
\hline Fat $(g)$ & 54 & 53 \\
\hline Protein $(\mathrm{g})$ & 115 & 133 \\
\hline Gl & 73 & 35 \\
\hline
\end{tabular}

*Cornflakes (Kellogg's, Melbourne, Australia); White bread (Sunblest, Tip Top bakeries, Sydney, Auystralia); Jam (Cottees strawberry conserve, Cottees, Melbourne, Australia); Margarine (Devondale extra soft spread, Murray Goulburn, Melbourne, Australia); Carbonated glucose drink (Lucozade, GlaxoSmithKleine, Boronia, Australia); Guardian Cereal (Kellogg's, Melbourne, Australia); Canned peaches (Goulburn Valley peach slices in natural juice (no added sugar); Yoghurt (Yoplait no fat fruit yoghurt, strawberry flavour if possible; National Foods, Sydney, Australia); Apple juice (Coles Farmland Apple Juice, no added sugar; Coles, Melbourne, Australia); Chicken (Castlemain shaved chicken breast, $97 \%$ fat free; KR Castlemaine, Castlemaine, Australia); Cheese (Coles Farmland tasty cheddar cheese; Coles, Melbourne, Australia); Wholemeal pasta (San Remo wholemeal pasta spirals; San Remo, Sydney, Australia); Tomato sauce (Dolmio, Sydney, Australia); Grain snack bar (K-Time mixed berry bars; Kellogg's, Melbourne, Australia); Fruit snack (Arnott's Snack right fruit slice, sultana; Arnott's, Sydney, Australia). 
stoichiometric equations ${ }^{27}$. At rest and during each of the expired gas collections, $5 \mathrm{ml}$ blood was collected into EDTA tubes and immediately centrifuged for $10 \mathrm{~min}$ at $4^{\circ} \mathrm{C}$. Plasma was then extracted and stored at $-80^{\circ} \mathrm{C}$ for later analysis.

\section{Intramyocellular lipid assessment}

With the subject supine, a vitamin-E capsule was placed equidistant between the caudal tip of the patella and the caudal head of the femur over the vastus lateralis and marked with indelible ink. Image-guided (from the vitamin-E capsule), localised proton magnetic resonance spectra of the right vastus lateralis muscle were generated on a 1.5 Tesla Philips magnetic resonance scanner (Philips Medical Systems, Best, The Netherlands). The subject lay on his right-hand side with a $10 \mathrm{~cm} \mathrm{C} 3$ flex coil (Philips Medical Systems, Best, The Netherlands) positioned over the vitamin-E capsule. The magnetic field was optimised using a fully automated shim routine to ensure magnetic field homogeneity. Water suppressed and unsuppressed spectra were collected from a $1.5 \times 1.5 \times 2.0 \mathrm{~cm}^{2}$ voxel using point resolved echo sequence spectroscopy (PRESS; echo time $32 \mathrm{~ms}$, relaxation time $5 \mathrm{~s}$ ).

\section{Quantifictation of spectra}

Calculation of metabolite (from water-suppressed spectra) and water (from water-unsupressed spectra) resonances was performed using the java-based magnetic resonance user interface (jMRUI version 2.0 $)^{28,29}$. Following manual first and second order phase correction, spectra were analysed using a nonlinear least squares algorithm (AMARES) ${ }^{30}$. With creatine $\mathrm{CH}-3$ resonance selected as a reference at $3.02 \mathrm{ppm}$, eight other resonances were calculated: $\mathrm{IMCL}-\mathrm{CH}_{3}(0.88 \mathrm{ppm})$, extra-myocellular lipid (EMCL)- $\mathrm{CH}_{3}(1 \cdot 19 \mathrm{ppm}), \mathrm{IMCL}^{-\mathrm{CH}_{2}}$ $(1.28 \mathrm{ppm})$, EMCL-CH $\mathrm{CH}_{2}(1.53)$, L-acetate 2.08 , fatty acid$\mathrm{CH}_{2}$ (2.24 ppm), trimethylacetate group (3.19 ppm), and taurine $(3.37 \mathrm{ppm})$. From the non-water suppressed spectra, only the water peak was quantified. The signal amplitude IMCL$\mathrm{CH}_{2}$ was corrected for $\mathrm{T}^{31,32}$ and $\mathrm{T}^{33}$ relaxation times reported in the literature under equivalent conditions. For absolute quantification of IMCL, metabolites were then corrected for proton content and the $\mathrm{IMCL}-\mathrm{CH}_{2}$ : water ratio (from the unsuppressed water spectra). Values were then converted into $\mathrm{mm} / \mathrm{kg}$ wet weight, assuming a water concentration of $55 \mathrm{~mm} / \mathrm{kg}$ wet weight and a tissue water fraction of $0 \cdot 81$, as previously described ${ }^{34}$ (CV $0.71 \mathrm{~mm} / \mathrm{kg}$ wet weight).

\section{Blood assays}

Plasma samples were analysed for glucose using a hexokinase enzymatic assay (Roche Diagnostic Systems, Sydney, Australia); insulin by a solid-phase, antibody-coated tube radioimmunoassay (Coat-A-Count Insulin RIA kit, Diagnostic Products Corporation, Los Angeles, CA, USA); lactate by enzymatic test (Roche Diagnostic Systems); glycerol using a colorimetric assay (RANDOX Laboratories Ltd, Crumlin, UK); free fatty acids (FFA) by a commercially available enzymatic colorimetric test kit (NEFA-HA; Wako Pure Chemical Industries Ltd, Osaka, Japan).

\section{Statistical analysis}

All statistical calculations were performed using SPSS version 11 (SPSS Inc., Chicago, IL, USA). A two-way analysis of variance (time and treatment) was used to assess metabolic and physiological differences between groups. A post-hoc Bonferroni step-wise correction was performed at the location of the variance. Statistical significance was accepted at $P<0.05$. Data are presented as means with their standard error unless otherwise stated.

\section{Results}

\section{Substrate oxidation}

Whole-body fat oxidation increased and carbohydrate oxidation decreased over the $90 \mathrm{~min}$ of exercise (Fig. 1). During the HGI trial 197 (SEM 23) g carbohydrate and 63 (SEM 5) g fat were oxidised. During the LGI trial, 169 (SEM 11) g carbohydrate and 76 (SEM 9)g fat were oxidised. Lipid oxidation represented 37 (SEM 6) \% of the total substrate oxidation in the HGI trial and 47 (SEM 8) \% in the LGI trial. Despite trends in the predicted direction, none of the differences in substrate oxidation reached statistical significance (area under curve, $P=0 \cdot 13$ ).

\section{Blood parameters}

After an early decline, plasma FFA showed a progressive rise throughout exercise in both HGI (0.32 (SEM 0.06) at baseline to 0.67 (SEM 0.05) $\mathrm{mm} / 1, P<0.01$ ) and LGI groups $(0.57$ (SEM 0.14 ) at baseline to 0.81 (SEM 0.11) $\mathrm{m} / \mathrm{l}, P<0 \cdot 01$ ) (Fig. 2 (A)). For the first $60 \mathrm{~min}$ of exercise, levels of circulatory FFA were higher in the LGI trial than in the HGI trial $(P<0.05$; Fig. 2 (A)). Plasma glycerol concentrations showed a progressive rise throughout exercise in the LGI (84 (SEM 17) at baseline to 483 (SEM 48) $\mu \mathrm{M} / 1, P<0 \cdot 01$ ) and HGI trials (88 (SEM 32) at baseline to $341 \mu \mathrm{M} / 1, P<0 \cdot 05$ ), with higher concentrations shown in the LGI group at 15 and $90 \mathrm{~min}$ $(P<0.05$; Fig. 2 (B)).

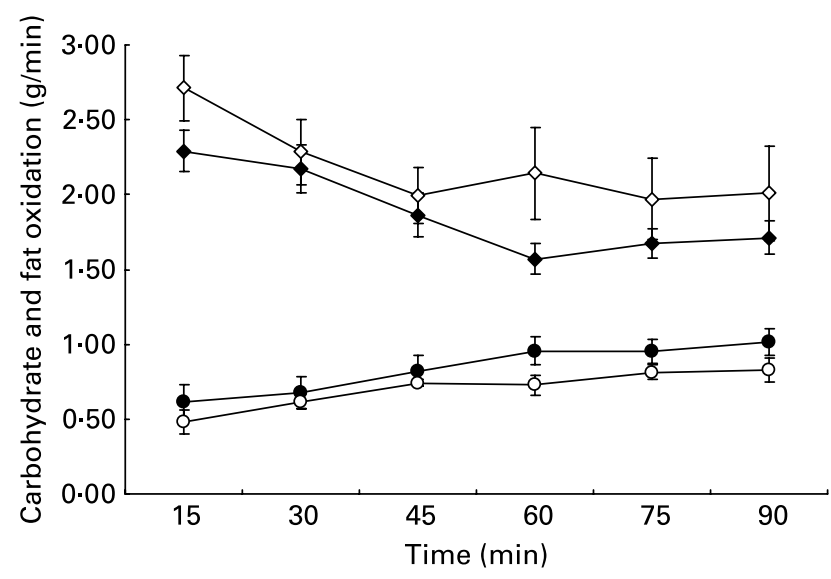

Fig. 1. Calculated carbohydrate $(\diamond, \diamond)$ and fat oxidation $(\bigcirc, \bullet)$ every $15 \mathrm{~min}$ whilst cycling at $70 \% \dot{\mathrm{V}} \mathrm{O}_{2 \text { peak }}$ following a high glycaemic index $(\diamond, \bigcirc)$ or low glycaemic index $(\bullet, \bullet)$ diet. Values are means with their standard errors shown by vertical bars. 
(A)

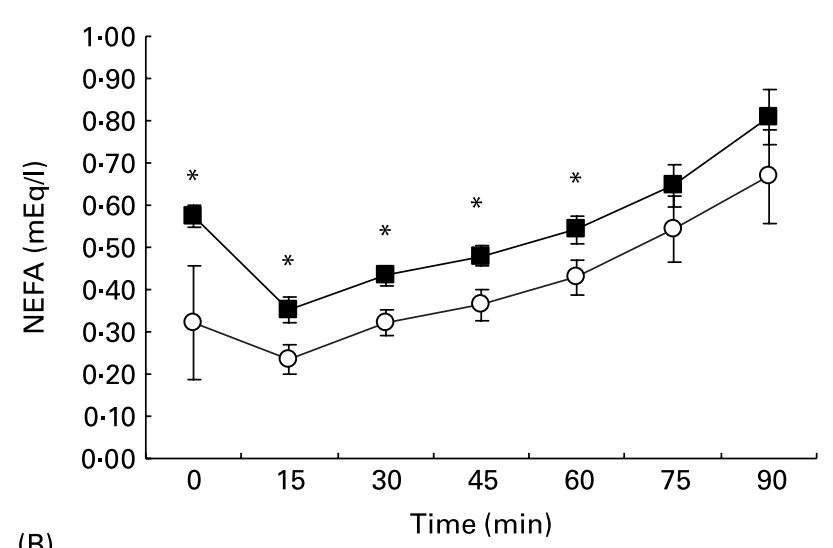

(B)

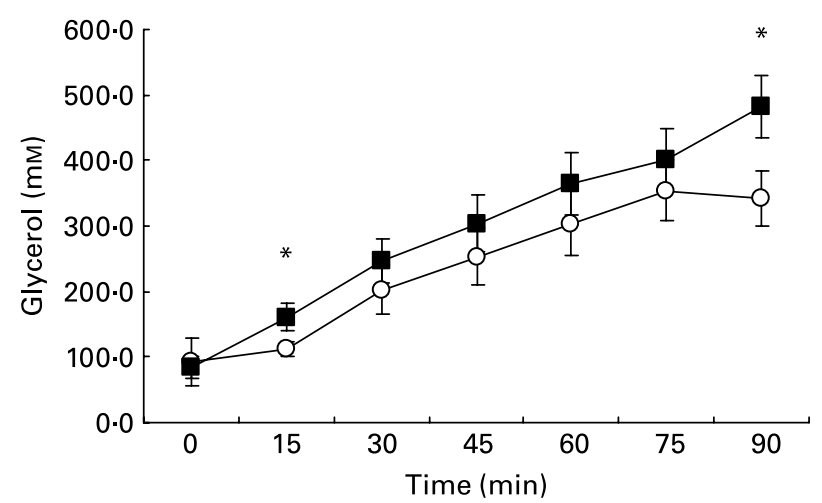

Fig. 2. Plasma NEFA (A) and glycerol (B) at rest and every 15 min whilst cycling at $70 \% \dot{\mathrm{VO}}_{2 \text { peak }}$ following a high glycaemic index ( $\mathrm{HGl}$; O) or low glycaemic index (LGl; $\mathbf{\square})$ diet. Values are means with their standard errors shown by vertical bars. Mean values were significantly different from HGI relevant time point: ${ }^{\star} P<0.05$.

After an initial $45 \mathrm{~min}$ stability, there was a progressive decline in circulating glucose $(P<0 \cdot 01$; Fig. 3 (A)). Plasma glucose concentrations were higher in the LGI trial at 75 and $90 \mathrm{~min}(P<0.05$; Fig. 2 (A)). Insulin concentrations decreased progressively throughout exercise in both trials $(P<0.01$; Fig. 3 (B)). After an initial rise from baseline, lactate concentrations remained stable throughout both trials (Fig. $3(\mathrm{C})$ ). Although mean lactate concentrations were consistently higher in the HGI trial, this did not achieve significance $(P=0 \cdot 07)$. Plasma cortisol levels increased through exercise although there were no differences between the HGI and LGI trial ( $P>0.05$; Fig. 3 (D)).

\section{Intramyocellular lipid}

Exercise produced a significant reduction in IMCL in both the HGI (from 7.3 (SEM 1.4) at baseline to 3.8 (SEM 0.9) $\mathrm{mM} / \mathrm{kg}$ wet weight, $P<0.05$ ) and LGI (from 5.9 (SEM 0.8) at baseline to 4.4 (SEM 0.8 ) $\mathrm{mm} / \mathrm{kg}$ wet weight, $P<0.05$ ) groups over the 90 min of exercise (Fig. 4). The HGI group therefore showed a greater dependence on IMCL (3.5 (SEM 1.0) $\mathrm{mm} / \mathrm{kg}$ wet weight) than the LGI group $(1.6(\mathrm{SEM} 0.3) \mathrm{mm} / \mathrm{kg}$ wet weight; Fig. 4). There was no significant difference between baseline IMCL $(P=0.08)$ or end exercise IMCL $(P=0.06)$ between the LGI and HGI groups.
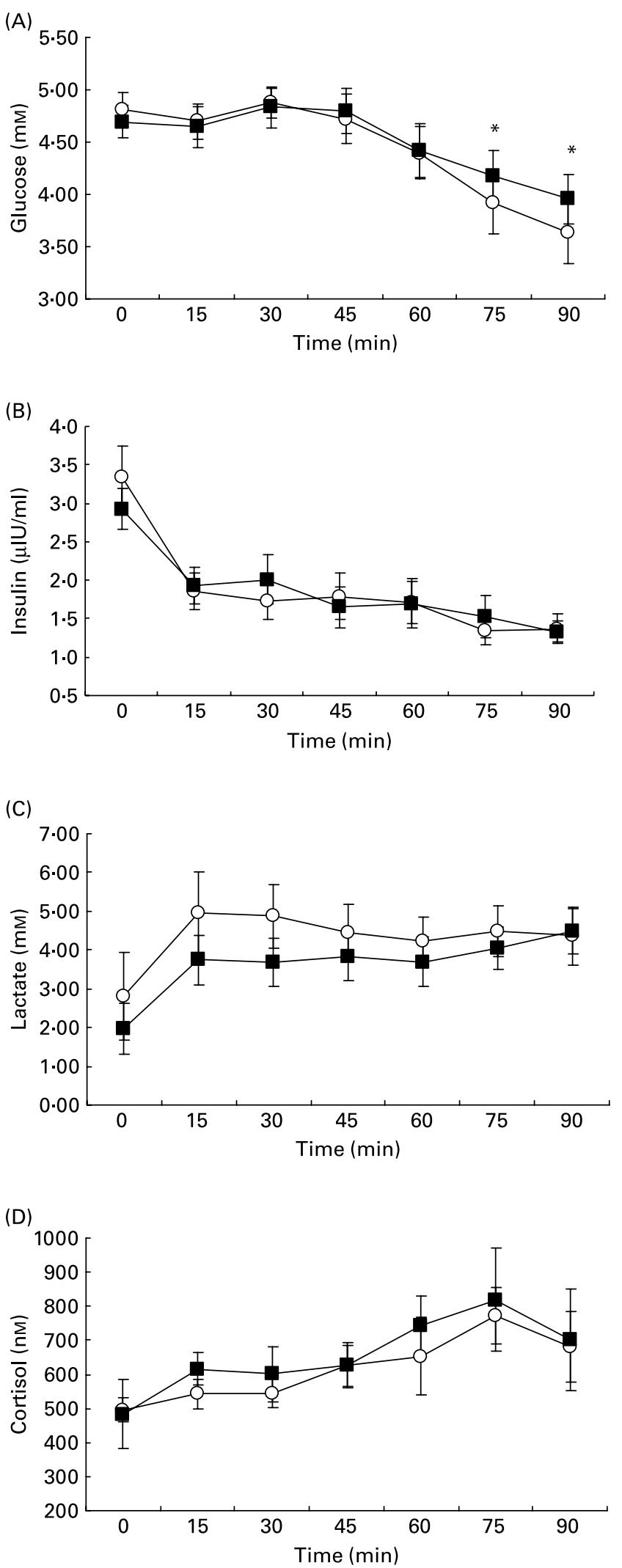

Fig. 3. Plasma glucose (A), insulin (B), lactate (C) and cortisol (D) at rest and every $15 \mathrm{~min}$ whilst cycling at $70 \% \dot{\mathrm{VO}}_{2 \text { peak }}$ following a high glycaemic index (HGl; O) or low glycaemic index (LGl; $\mathbf{\square})$ diet. Values are means with their standard errors shown by vertical bars. Mean values were significantly different from HGI relevant time point: ${ }^{\star} P<0.05$. 


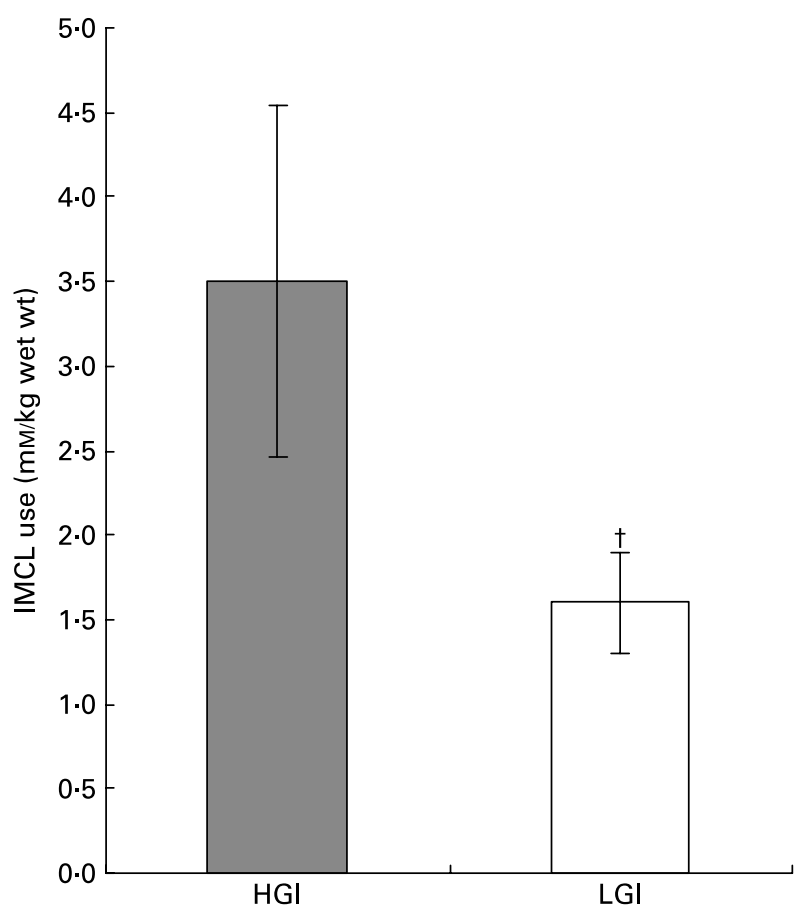

Fig. 4. Intramyocellular lipid (IMCL) use whilst cycling at $70 \% \dot{\mathrm{V}} \mathrm{O}_{2 \text { peak }}$ following a high $(\mathrm{H})$ or low (L) glycaemic index (GI) diet. Values are means with their standard errors shown by vertical bars. Mean values were significantly different from HGI. $\dagger P<0.05$.

\section{Discussion}

This study shows that the GI of the diet consumed in the recovery period influences substrate availability and utilisation in subsequent prolonged exercise. Circulating fatty acid availability during exercise was about $34 \%$ greater following a LGI diet compared with the HGI diet (quantified as area under the curve). The use of IMCL as a substrate source was $>2$-fold higher after the HGI meals than the LGI meals. Combined, these results suggest that consuming a LGI diet between bouts of prolonged strenuous exercise reduces dependence on intramuscular lipid stores and increases the use of circulating plasma FFA derived from other fat stores as a fuel source. In competitive sports and search-and-rescue operations, LGI meals might therefore improve final outcomes.

A novel aspect of the current study is the use of MRS to assess changes in IMCL following carbohydrate manipulation. The LGI diet was associated with a decreased IMCL oxidation and increased NEFA availability during exercise. In contracting skeletal muscle, the rate of NEFA uptake and oxidation is increased, preserving IMCL stores ${ }^{22}$. At rest, plasma NEFA are esterified in skeletal muscle to form IMCL ${ }^{22,35}$. Indeed, dietary intakes high in fat (40-60\% fat) promote IMCL storage $^{36-38}$ while diets high in carbohydrate $(5-25 \%$ fat) reduce IMCL storage $\mathrm{e}^{38,39}$.

Although the amount of IMCL oxidised during exercise was different between the treatment groups, the HGI group had a higher mean IMCL content before exercise and lower IMCL content after exercise, though these did not achieve statistical significance $(P=0.08$ and $P=0.06$ respectively).
It is possible that the higher starting levels of IMCL in the HGI group could aid subsequent IMCL oxidation ${ }^{9}$, theoretically, through an increase in the substrate-enzyme interface $^{40}$. The higher starting levels of IMCL in the HGI group would appear paradoxical, as a HGI diet should decrease NEFA availability to replenish IMCL in recovery from exercise ${ }^{19}$. However, the design of the present study cannot conclusively provide any explanation for these observations, as the study: (1) may be underpowered to detect changes in IMCL storage between groups, and (2) did not track postprandial lipid availability and oxidation over the recovery period. Irrespective of these comments, our data suggest that not only is the amount of carbohydrate and fat intake influential in determining substrate storage and use, but that the GI of the carbohydrate can change the availability and use of lipids during exercise. The observation of a trend towards differences in IMCL at the start and end of exercise between diets reinforces the need for further studies observing the influence of postprandial signalling and lipid availability upon IMCL storage.

Analysis of the indirect calorimetry data shows that there is a progressive increase in lipid oxidation and a decline in carbohydrate oxidation over the exercise period. The decline in carbohydrate utilisation has been attributed to a decrease in muscle glycogen utilisation and an increased uptake and use of plasma glucose ${ }^{6}$. Conversely, as plasma NEFA availability is reported to determine NEFA oxidation ${ }^{21}$, the progressive rise in plasma NEFA is likely to reflect an increase in NEFA oxidation. Studies using Intralipid infusion to elevate plasma NEFA concentrations show an increase in lipid oxidation and a reduced glycogen use in exercise ${ }^{10-13}$, suggesting that FFA availability can influence substrate use in skeletal muscle. In further support, use of the antilipolytic agent nicotinic acid reduces plasma fatty acid and increases dependence on glycogen during exercise ${ }^{41}$. Despite this evidence, the pathways which control the relative contribution of carbohydrate and fat as substrate sources during metabolism are not completely understood ${ }^{42}$. However, the sustained suppression of circulating FFA during prolonged exercise may in part explain the increased reliance upon IMCL as a substrate source following a HGI diet.

Elevated insulin concentrations suppress lypolysis at rest and during subsequent exercise, reducing circulating levels of $\mathrm{NEFA}^{17}$. In line with this, acute intake of carbohydrate before exercise $(<4 \mathrm{~h})$ has been shown to decrease FFA availability and increase glycogen dependence during exercise $\mathrm{e}^{25}$. Altering the GI of carbohydrates consumed before exercise has been shown to influence substrate oxidation during exercise. Studies have reported that consuming a LGI breakfast $3 \mathrm{~h}$ before endurance exercise resulted in an increase in FFA availability and hence an increase in fat oxidation and decrease in carbohydrate oxidation compared to when a HGI breakfast is consumed ${ }^{18,43,44}$. In the current study, an increase in FFA availability was observed during exercise the day after consuming a LGI diet. Interestingly, the elevated circulatory NEFA observed at rest and during exercise in the LGI group occurred independent of any differences in circulating insulin between the treatment groups. This is suggestive of heightened or dampened sensitivity of the adipose tissue to insulin following exposure to high (HGI) or moderate (LGI) exposure to insulin ${ }^{45}$, respectively, the previous day. 
Plasma glucose levels were stable over the first $45 \mathrm{~min}$ of exercise but then steadily declined. In the final $30 \mathrm{~min}$, the decline was attenuated in the LGI group in comparison to the HGI group. It is likely that the difference represents increased dependence on glucose as the source of fuel in the HGI group ${ }^{46}$. It is possible that both liver and muscle glycogen stores are being depleted faster but little is known about the relative roles of each. Liver glycogen stores appear to be important. Using ${ }^{13} \mathrm{C}$ magnetic resonance spectorscopy ${ }^{47}$, glycogen content of the liver following exhaustive exercise was found to predict subsequent exercise capacity. Further ${ }^{13} \mathrm{C}$-MRS studies are needed to determine the relative importance of different fuel sources.

Our observation of a significant decrease in IMCL in both LGI and HGI groups with $90 \mathrm{~min}$ of exercise demonstrates that IMCL is a major substrate source during prolonged exercise. This observation is in line with previous studies using isotope-labelled $\mathrm{FFA}^{5,9}$, muscle biopsy ${ }^{6,9}$ and magnetic resonance $e^{6,7,9}$ analysis techniques. The use of IMCL as a substrate source during exercise has been the subject of much recent debate, with the inability of early studies to discriminate between intra- and extra-cellular lipids using biochemical analysis being central to this misunderstanding $^{48}$. The problem is clearly demonstrated by Howald et $a l^{49}$ who showed strong correlation between electron microscopic morphometry and MRS ( $r$ 0.93), demonstrating that both of these techniques are accurate in determining IMCL. However, the correlation between IMCL determined by biochemical analysis from muscle biopsy was weak with electron microscopic morphometry $(r$ 0.41) and MRS ( $r$ 0.47). Our findings show that not only is IMCL (as assessed by ${ }^{1} \mathrm{H}-\mathrm{MRS}$ ) an important substrate during exercise, but also that the origin of lipid oxidised during exercise, whether intra- or extra-muscular, can be influenced by the composition of diet during the previous $24 \mathrm{~h}$. Future studies combining the use of ${ }^{1} \mathrm{H}$-MRS measurement of IMCL with ${ }^{13} \mathrm{C}$-MRS measurements of glycogen will add further to our understanding of this complex area.

In summary, the GI of carbohydrates consumed after prolonged exercise had a significant effect on substrate utilisation during subsequent exercise. The availability of plasma FFA was increased and IMCL use decreased when a LGI diet was consumed over a $24 \mathrm{~h}$ period compared to when a HGI diet was consumed. Further research is required to investigate whether the change in lipid oxidation with diets differing in GI alters glycogen usage and whether these changes in turn hold benefits for endurance-exercise performance.

\section{Acknowledgements}

The authors thank the volunteers for their participation and dedication. We also thank Helen Lackey, Jacquie Stewart, Dr John Magnusson and Dr Geoff Parker from Specialist Magnetic Resonance Imaging for assistance with magnetic resonance studies, The Woolcock Institute for Medical Research and Professor Carolyn Sue for access to exercise-testing facilities. This work was financially supported by the Sydney University Glycemic Index Research Service (SUGiRS).

\section{References}

1. Bergstrom JEH (1966) Muscle glycogen synthesis after exercise: an enhancing factor localized to the muscle cells in man. Nature 210, 5033, 309-310.

2. Bergstrom J, Hermansen L, Hultman E \& Saltin B (1967) Diet, muscle glycogen and physical performance. Acta Physiol Scand 71, 2, 140-150.

3. Walker JL, Heigenhauser GJF, Hultman E \& Spriet LL (2000) Dietary carbohydrate, muscle glycogen content, and endurance performance in well-trained women. $J$ Appl Physio 88, 6, 2151-2158.

4. Coyle EF, Coggan AR, Hemmert MK \& Ivy JL (1986) Muscle glycogen utilization during prolonged strenuous exercise when fed carbohydrate. J Appl Physiol 61, 1, 165-172.

5. Romijn JA, Coyle EF, Sidossis LS, Gastaldelli A, Horowitz JF, Endert E, et al. (1993) Regulation of endogenous fat and carbohydrate metabolism in relation to exercise intensity and duration. Am J Physiol Endocrinol Metab 265, 3, E380-E391.

6. van Loon LJC, Koopman R, Stegen JHCH, Wagenmakers AJM, Keizer HA \& Saris WHM (2003) Intramyocellular lipids form an important substrate source during moderate intensity exercise in endurance-trained males in a fasted state. $J$ Physiol 553, 2, 611-625.

7. Johnson NA, Stannard SR, Mehalski K, Trenell MI, Sachinwalla $\mathrm{T}$, Thompson $\mathrm{CH}$, et al. (2003) Intramyocellular triacylglycerol in prolonged cycling with high- and low-carbohydrate availability. J Appl Physiol 94, 4, 1365-1372.

8. van Loon LJC \& Goodpaster BH (2006) Increased intramuscular lipid storage in the insulin-resistant and endurance-trained state. Pflugers Arch V451, 5, 606-616.

9. Stellingwerff T, Boon H, Jonkers RAM, Senden JM, Spriet LL, Koopman R, et al. (2007) Significant intramyocellular lipid use during prolonged cycling in endurance trained males as assessed by three different methodologies. Am J Physiol Endocrinol Metab, Epub (May 2007), DOI 10.1152/ajpendo.00678.2006.

10. Dyck DJ, Putman CT, Heigenhauser GJ, Hultman E \& Spriet LL (1993) Regulation of fat-carbohydrate interaction in skeletal muscle during intense aerobic cycling. Am J Physiol Endocrinol Metab 265, 6, E852-E859.

11. Dyck DJ, Peters SJ, Wendling PS, Chesley A, Hultman E \& Spriet LL (1996) Regulation of muscle glycogen phosphorylase activity during intense aerobic cycling with elevated FFA. Am J Physiol Endocrinol Metab 270, 1, E116-E125.

12. Odland LM, Heigenhauser GJF, Wong D, Hollidge-Horvat MG \& Spriet LL (1998) Effects of increased fat availability on fatcarbohydrate interaction during prolonged exercise in men. $\mathrm{Am}$ J Physiol Regul Integr Comp Physiol 274, 4, R894-R902.

13. Odland LM, Heigenhauser GJF \& Spriet LL (2000) Effects of high fat provision on muscle PDH activation and malonylCoA content in moderate exercise. J Appl Physiol 89, 6, 2352-2358.

14. Costill D, Sherman W, Fink W, Maresh C, Witten M \& Miller J (1981) The role of dietary carbohydrates in muscle glycogen resynthesis after strenuous running. Am J Clin Nutr 34, 9, $1831-1836$

15. Ivy JL, Lee MC, Brozinick JT Jr \& Reed MJ (1998) Muscle glycogen storage after different amounts of carbohydrate ingestion. J Appl Physiol 65, 5, 2018-2023.

16. Burke LM, Collier GR \& Hargreaves M (1993) Muscle glycogen storage after prolonged exercise: effect of the glycemic index of carbohydrate feedings. J Appl Physiol 75, 2, 1019-1023.

17. Horowitz JF, Mora-Rodriguez R, Byerley LO \& Coyle EF (1997) Lipolytic suppression following carbohydrate ingestion limits fat oxidation during exercise. Am J Physiol Endocrinol Metab 273, 4, E768-E775. 
18. Wu C-L, Nicholas C, Williams C, Took A \& Hardy L (2003) The influence of high-carbohydrate meals with different glycaemic indices on substrate utilisation during subsequent exercise. Brit J Nutr 90, 6, 1049-1056.

19. Stevenson EJ, Williams C, McComb G \& Oram C (2005) Improved recovery from prolonged exercise following the consumption or low glycmeic index carbohydrate meals. Int J sport Nutr Ex Metab 15, 4, 333-349.

20. van Loon LJC, Thomason-Hughes M, Constantin-Teodosiu D, Koopman R, Greenhaff PL, Hardie DG, et al. (2005) Inhibition of adipose tissue lipolysis increases intramuscular lipid and glycogen use in vivo in humans. Am J Physiol Endocrinol Metab 289, 3, E482-E493.

21. Romijn JA, Coyle EF, Sidossis LS, Zhang XJ \& Wolfe RR (1995) Relationship between fatty acid delivery and fatty acid oxidation during strenuous exercise. J Appl Physiol 79, 6, 1939-1945.

22. Sacchetti M, Saltin B, Osada T \& van Hall G (2002) Intramuscular fatty acid metabolism in contracting and non-contracting human skeletal muscle. J Physiol 540, 1, 387-395.

23. Coyle EF, Jeukendrup AE, Wagenmakers AJ \& Saris WH (1997) Fatty acid oxidation is directly regulated by carbohydrate metabolism during exercise. Am J Physiol Endocrinol Metab 273, 2, E268-E275.

24. van Loon LJC (2004) Use of intramuscular triacylglycerol as a substrate source during exercise in humans. J Appl Physiol 97, 4, 1170-1187.

25. Montain S, Hopper M, Coggan A \& Coyle E (1991) Exercise metabolism at different time intervals after a meal. $J$ App Physiol 70, 2, 882-888.

26. Foster-Powell K, Holt SH \& Brand-Miller JC (2002) International table of glycemic index and glycemic load values. Am J Clin Nutr 76, 1, 5-56.

27. Frayn K (1983) Calculation of substrate oxidation rates in vivo from gaseous exchange. J App Physiol 55, 2, 628-634.

28. Naressi A, Couturier C, Castang I, de Beer R \& GraveronDemilly D (2001) Java-based graphical user interface for MRUI, a software package for quantitation of in vivo/medical magnetic resonance spectroscopy signals. Comp Biol Med 31, $4,269-286$.

29. Naressi A, Couturier C, Devos JM, Janssen M, Mangeat C, de Beer R, et al. (2001) Java-based graphical user interface for the MRUI quantitation package. Magma 12, 2-3, 141-152.

30. Vanhamme L, Van Huffel S, Van Hecke P \& van Ormondt D (1999) Time-domain quantification of series of biomedical magnetic resonance spectroscopy signals. J Mag Res 140, 1, 120-130.

31. Bruhn H, Frahm J, Gyngell ML, Merboldt KD, Hanicke W \& Sauter R (1991) Localized proton NMR spectroscopy using stimulated echoes: applications to human skeletal muscle in vivo. Magn Reson Med 17, 1, 82-94.

32. Schick F, Eismann B, Jung WI, Bongers H, Bunse M \& Lutz O (1993) Comparison of localized proton NMR signals of skeletal muscle and fat tissue in vivo: two lipid compartments in muscle tissue. Mag Res Med 29, 2, 158-167.

33. Stannard SR, Thompson MW, Fairbairn K, Huard B, Sachinwalla $\mathrm{T} \&$ Thompson CH (2002) Fasting for $72 \mathrm{~h}$ increases intramyocellular lipid content in nondiabetic, physically fit men. Am J Physiol 283, 6, E1185-E1191.

34. Szczepaniak LS, Babcock EE, Schick F, Dobbins RL, Garg A, Burns DK, et al. (1999) Measurement of intracellular triglyceride stores by $\mathrm{H}$ spectroscopy: validation in vivo. Am J Physiol Endocrinol Metab 276, 5, E977-E989.

35. van Hall G, Sacchetti M, Radegran G \& Saltin B (2002) Human skeletal muscle fatty acid and glycerol metabolism during rest, exercise and recovery. $J$ Physiol 543, 3, 1047-1058.

36. Zderic TW, Davidson CJ, Schenk S, Byerley LO \& Coyle EF (2004) High-fat diet elevates resting intramuscular triglyceride concentration and whole body lipolysis during exercise. Am $J$ Physiol Endocrinol Metab 286, 2, E217-E225.

37. Helge JW, Watt PW, Richter EA, Rennie MJ \& Kiens B (2001) Fat utilization during exercise: adaptation to a fat-rich diet increases utilization of plasma fatty acids and very low density lipoprotein-triacylglycerol in humans. $J$ Physiol 537, 3, 1009-1020.

38. Starling RD, Trappe TA, Parcell AC, Kerr CG, Fink WJ \& Costill DL (1997) Effects of diet on muscle triglyceride and endurance performance. J Appl Physiol 82, 4, 1185-1189.

39. Coyle EF, Jeukendrup AE, Oseto MC, Hodgkinson BJ \& Zderic TW (2001) Low-fat diet alters intramuscular substrates and reduces lipolysis and fat oxidation during exercise. Am J Physiol Endocrinol Metab 280, 3, E391-E398.

40. Prats C, Donsmark M, Qvortrup K, Londos C, Sztalryd C, Holm C, et al. (2006) Decrease in intramuscular lipid droplets and translocation of HSL in response to muscle contraction and epinephrine. J Lipid Res 47, 11, 2392-2399.

41. Stellingwerff T, Watt MJ, Heigenhauser GJF \& Spriet LL (2003) Effects of reduced free fatty acid availability on skeletal muscle PDH activation during aerobic exercise. Am J Physiol Endocrinol Metab 284, 3, E589-E596.

42. Wolfe R (1998) Metabolic interactions between glucose and fatty acids in humans. Am J Clin Nutr 67, 3, 519S-526S.

43. Stevenson EJ, Williams C, Mash LE, Phillips B \& Nute ML (2006) Influence of high-carbohydrate mixed meals with different glycemic indexes on substrate utilization during subsequent exercise in women. Am J Clin Nutr 84, 2, 354-360.

44. Wee S-L, Williams C, Tsintzas K \& Boobis L (2005) Ingestion of a high-glycemic index meal increases muscle glycogen storage at rest but augments its utilization during subsequent exercise. J Appl Physiol 99, 2, 707-714.

45. Kallio P, Kolehmainen M, Laaksonen DE, Kekalainen J, Salopuro T, Sivenius K, et al. (2007) Dietary carbohydrate modification induces alterations in gene expression in abdominal subcutaneous adipose tissue in persons with the metabolic syndrome: the FUNGENUT Study. Am J Clin Nutr 85, 5, $1417-1427$.

46. Stevenson EJ, Williams C \& Nute ML (2005) The influence of the glycaemic index of breakfast and lunch on substrate utilisation during the postprandial periods and subsequent exercise. Brit J Nutr 93, 885-893.

47. Casey A, Mann R, Banister K, Fox J, Morris PG, Macdonald IA, et al. (2000) Effect of carbohydrate ingestion on glycogen resynthesis in human liver and skeletal muscle, measured by 13C MRS. Am J Physiol Endocrinol Metab 278, 1, E65-E75.

48. Watt MJ, Heigenhauser GJF \& Spriet LL (2002) Intramuscular triacylglycerol utilization in human skeletal muscle during exercise: is there a controversy? $J$ Appl Physiol 93, 4, $1185-1195$.

49. Howald H, Boesch C, Kreis R, Matter S, Billeter R, EssenGustavsson B, et al. (2002) Content of intramyocellular lipids derived by electron microscopy, biochemical assays, and (1)H-MR spectroscopy. J Appl Physiol 92, 6, 2264-2272. 